\title{
Perception of stability correlates with objective performance of dynamic stability for people with chronic ankle instability
}

\author{
L. Forsyth ${ }^{1}$ (1) F. Pourkazemi ${ }^{2}$ S. Al Adal ${ }^{3} \cdot$ C. E. Hiller ${ }^{2} \cdot$ C. R. Childs ${ }^{1}$
}

Received: 10 September 2021 / Accepted: 19 October 2021 / Published online: 2 November 2021

(c) The Author(s) 2021

\begin{abstract}
Purpose Lateral ankle sprains are one of the most prevalent musculoskeletal injuries, with one of the highest recurrence rates. One in five people develops chronic ankle instability (CAI) after a lateral ankle sprain. CAI is mainly described as a subjective phenomenon, but is associated with recurrent symptoms, reduced dynamic stability, and reduced physical activity and quality of life. Understanding the relationship between perception of stability and effect on performance for people with CAI could inform rehabilitative strategies in clinical practice. This study aimed to investigate the relationship between the perception of stability and objective performance of dynamic stability this population.

Methods This study is a sub-analysis of data from four separate studies in Australia and the United Kingdom. Participants were screened and categorised as a CAI, coper, or healthy participant. Each participant completed the Star Excursion Balance Test (SEBT) and Cumberland ankle instability tool (CAIT). Distances reached in the anterior, posterior-medial, and posterior-lateral directions, and average, of the SEBT were analysed.

Results Data from 95 participants with CAI, 45 copers, and 101 healthy participants was analysed. There was a significant moderate correlation between CAIT score and SEBT reach distance in all directions for the CAI group $(p<0.001)$. For copers, there was small significant correlation in the posterior-lateral direction $(p<0.05)$.

Conclusion This study highlights the discrepancies between the perception of stability and objective dynamic stability, and reinforces the importance of using both types of measures for continual assessment in practice to optimise selecting rehabilitative strategies.
\end{abstract}

Keywords Star excursion balance test $\cdot$ Cumberland ankle instability tool · Chronic ankle instability · Ankle sprains · Ankle instability $\cdot$ Perception

\section{Introduction}

In sport and military populations, lateral ankle sprains (LAS) are the most prevalent musculoskeletal injury, but LAS are also extremely common among the general population $[1,2]$. The perception that LAS are benign injuries has led to only around $55 \%$ of people seeking medical treatment following injury $[3,4]$, and for those who do, there is a lack

L. Forsyth

lauren.forsyth@strath.ac.uk

1 Faculty of Biomedical Engineering, University of Strathclyde, Glasgow, UK

2 Faculty of Medicine and Health, The University of Sydney, Sydney, Australia

3 Faculty of Applied Medical Sciences, Najran University, Najran, Saudi Arabia of consensus for the rehabilitation process and adherence to the process. LAS has one of the highest recurrence rates of all musculoskeletal injuries [2, 5]. As a result, research has shown that one in five people develop chronic ankle instability (CAI) [6]. People with CAI experience recurrent and residual debilitating symptoms and have been shown to be more likely to develop ankle posttraumatic osteoarthritis [1]. As a chronic condition, CAI has been associated with reduced physical activity and quality of life, which can have further health implications to both physical and mental health $[1,7]$.

CAI is mainly described as a subjective phenomenon, whereby there is only a perception of instability and often no evidence of a mechanical deficit [8]. CAI has also been associated with a reduced postural control as performance in functional tests is reduced compared to people with no CAI [9]. However, for people with CAI, a subjective physical 
deficit alone decreased physical activity levels, even when there were no objective physical deficits [7, 9]. This highlights the importance of understanding both psychological—defined as feelings and perceptions-and physical performance in this population to ensure that rehabilitative strategies and patient discharges are appropriate. This relationship has been assessed before in Spanish recreational athletes with and without CAI [10]. The Star Excursion Balance Test (SEBT) was used to assess dynamic stability as a predictor for CAI and relate this to the Cumberland Ankle Instability Tool (CAIT). A small-moderate significant correlation was shown between the SEBT and the CAIT in the Spanish athletes with and without CAI, however, it remains unknown if this relationship holds true in a general population, or for people who have experienced an ankle sprain but not developed CAI (copers). This is important given the prevalence of ankle injuries in the general population worldwide [1,2].

Evidence of the impact on quality of life and performance of activities or sports from a mismatch in physical and psychological abilities has been particularly evident for return to play decisions in sport [11]. The decision is often based on the physical performance outcomes, and not considering the psychological readiness, despite the correlation between psychological factors and injury occurrence [12]. As an example, Ardern and colleagues [13] reported a higher number of athletes not returning to sport following ACL surgery because of psychological factors opposed to functional performance of the knee. This implies that a perception of low ankle stability may prevent someone from being physically active and performing daily activities, reducing quality of life, whereas a high perception of stability may lead to someone attempting tasks they are not capable of yet thus increasing risk of injury or re-injury. If the relationship between perception of stability and objective performance of dynamic stability is known, it will inform rehabilitative strategies in clinical practice and decisions regarding clinical discharge and return to activities. This relationship has yet to be investigated in the general population.

This study aimed to investigate the relationship between the perception of stability measured by CAIT and performance outcome of a test for dynamic stability measured by the SEBT. It was hypothesized that there should be a positive linear relationship between the measures of perceived stability and dynamic stability performance.

\section{Methods}

\section{Design}

This study is a sub-analysis of data from four separate studies [14-17]. Data from the four research studies across
Australia and the United Kingdom were pooled and analysed. The process of data collection is provided in detail in the published studies. The process is briefly explained here.

\section{Participants}

Participants in all studies were categorised into one of three groups: people with CAI, copers, and healthy participants.

Participants with CAI were screened using the International Ankle Consortium guidelines [18, 19]. Participants with CAI were required to have experienced all of the following: (1) history of at least one significant ankle sprain, (2) most recent injury to have occurred more than 3 months prior to study participation, (3) history of previous episodes of 'giving way', recurrent sprain, or 'feelings of instability', and (4) perceived ankle instability determined by a score of $\leq 25 / 30$ on the CAIT $[19,20]$. The CAIT was used to screen participants for CAI and quantify perception of stability.

Participants were considered as copers if they had sustained at least one ankle injury, reported no residual symptoms associated with the previous ankle sprain, and their CAIT score was $\geq 27$.

Participants were included in the healthy group if they had not sustained any previous ankle injuries and scored $\geq 27$ on the CAIT.

All participants were aged between 18 and 65 years. Participants with any other lower limb injuries, fractures, vestibular impairments, or any other health-related diagnosis that would impact their participation were excluded from the studies.

\section{Instrumentation and protocol}

The CAIT was used as a screening tool for all the studies, and it was, therefore, completed prior to the laboratory visits. The Cumberland Ankle Instability Tool (CAIT) is a recognised valid and reliable tool for assessing CAI where a lower score indicates a lower perception of stability (intraclass correlation coefficient $[\mathrm{ICC}]_{2,1}=0.96$ ) [20].

At the testing session, demographic information such as age, body mass, leg dominance, physical activity levels, and sport participation, and ankle injury history were collected and the SEBT was completed. Participants wore comfortable clothing that was suitable for rehabilitative practice and performed the test barefoot.

The SEBT is an accepted and reliable method adopted in clinical practice to measure dynamic postural control of those with CAI [21-25]. It was completed while reaching to maximum distance in pre-determined directions, while maintaining unilateral stance and without shifting the weight from the supporting limb [22]. To guide movement, the reach directions were identified by tape on the floor. Hands 
remained on the hips throughout the performance/test. Loss of balance or failure to comply with the verbal instructions meant the trial was discarded and repeated. The SEBT was performed on both the affected and unaffected sides for up to four practice trials, to diminish learning effects, and up to three test trials of which either the best performance was analysed [15-17, 26, 27], or the average of the furthest two reaches was analysed [14].

For participants with bilateral CAI the ankle which had sustained a greater number of injuries and was perceived as more unstable as per the CAIT, was the ankle analysed. For the participants with no previous ankle injuries, the side which scored a lower reach distance on average was analysed.

\section{Statistical analysis}

The mean (SD) CAIT score and anterior, posterior-medial, and posterior-lateral reach distances for the SEBT were calculated.

All statistical analysis was performed using SPSS Statistics (SPSS Statistics v. 26, USA). Data Normality was tested using Kolmogorov-Smirnov test for normality. Data were not normally distributed for CAIT and so Spearman's correlation was used due to the non-parametric data. The strength of the correlation between the CAIT and SEBT scores for each direction was calculated using $(r)$. Partial correlations controlled for weight, age, and sex. The correlations

Table 1 Descriptive statistics for CAI, Coper, No-CAI participants

\begin{tabular}{llll}
\hline & CAI & Coper & Healthy \\
\hline Number of participants & 95 & 45 & 101 \\
Age (years) & $27(7.92)$ & $32.1(8.6)$ & $28(8.9)$ \\
Weight $(\mathrm{kg})$ & $72.71(17.13)$ & $67.55(12.87)$ & $66.54(14.06)$ \\
Sex (F/M) & $47 / 48$ & $19 / 26$ & $56 / 45$ \\
Ankle analysed (R/L & $55 / 40$ & $33 / 12$ & $56 / 45$ \\
\hline
\end{tabular}

Results are presented as mean (SD) for continuous data and number for dichotomous data

$F$ female, $M$ male, $R$ right, $L$ left were interpreted as weak: $0.3-0.49$; moderate: $0.5-0.79$ or strong: $\geq 0.8[28]$.

\section{Results}

Data from 95 participants with CAI, 45 copers, and 101 participants with no previous ankle injuries were analysed (Table 1).

For the CAI group, the median CAIT score was 21. For the coper and No-CAI groups, the median CAIT score was 29. Table 2 shows the mean results for the SEBT and CAIT for each group.

The relationship for CAI, Copers and No-CAI groups was unaffected when age, sex and weight were individually controlled for. The correlation between the CAIT score and each reach direction is shown in Table 3 and Figs. 1, 2, 3, and 4.

\section{Discussion}

For people with CAI, there was a significant moderate, positive correlation between the CAIT score and distances reached for all SEBT directions. This supports the hypothesis that there was a positive relationship between perception of stability and dynamic stability using the CAIT and SEBT.

The results for the CAI population agree with the results from Sierra-Guzman et al. [10] smaller sample of younger athletes with CAI. Results reported significant moderate correlations between SEBT performance and CAIT score in all directions, which was also greatest in the posterior-medial direction $(r=0.45, p=0.001)$. When different patientreported outcome measures were used for the CAI population (FAAM-ADL and FAAM-S and VAS for pain, stability, and function) a small correlation was reported, but this did not reach statistical significance [7]. This demonstrates the limited evidence that perception of stability and foot and ankle function incurs greater dynamic stability. Thus, the moderate correlation in this study highlights the importance of subjectively monitoring patients alongside objective assessments. This will maximise the potential for the
Table 2 Mean (SD) CAIT score and SEBT reach distances for all directions for CAI, Coper and No-CAI participants

\begin{tabular}{llll}
\hline & CAI & Coper & Healthy \\
\hline CAIT Score & $18.31(5.22)^{+}$ & $28.93(1.10)^{+}$ & $29.27(1.10)^{+}$ \\
SEBT A (\% leg length) & $72.37(11.04)$ & $74.62(11.04)$ & $70.69(9.98)^{+}$ \\
SEBT PL (\% leg length) & $69.04(16.63)^{+}$ & $74.22(11.30)$ & $67.92(12.91)^{+}$ \\
SEBT PM (\% leg length) & $79.75(18.09)$ & $85.55(13.48)$ & $77.06(16.88)$ \\
SEBT Average (\% leg length) & $73.75(14.00)^{+}$ & $78.13(10.76)$ & $72.00(11.39)^{+}$ \\
\hline
\end{tabular}

CAIT chronic ankle instability, SEBT Star Excusion Balance Test, $A$ anterior, $P L$ posterior-lateral, $P M$ posterior-medial

${ }^{+}$Non-parametric data 
Table 3 Pearson correlations for CAIT and A, PM, PL, and Average SEBT reach directions when uncontrolled and controlled for age, weight, and sex

\begin{tabular}{|c|c|c|c|c|c|c|c|c|}
\hline & \multicolumn{2}{|l|}{ SEBT A } & \multicolumn{2}{|l|}{ SEBT PL } & \multicolumn{2}{|l|}{ SEBT PM } & \multicolumn{2}{|l|}{ SEBT average } \\
\hline & Uncontrolled & Controlled & Uncontrolled & Controlled & Uncontrolled & Controlled & Uncontrolled & Controlled \\
\hline CAI & $0.43 *$ & $0.40 *$ & $0.44 *$ & $0.40^{*}$ & $0.49 *$ & $0.42 *$ & $0.51 *$ & $0.43 *$ \\
\hline Coper & 0.10 & 0.13 & $0.34^{* *}$ & $0.35 * *$ & 0.20 & 0.23 & 0.23 & 0.26 \\
\hline Healthy & 0.12 & 0.10 & 0.05 & 0.04 & 0.15 & 0.14 & 0.13 & 0.12 \\
\hline
\end{tabular}

$C A I$ chronic ankle instability, SEBT Star Excusion Balance Test, $A$ anterior, $P L$ posterior-lateral, $P M$ posterior-medial

$* \operatorname{Sig} p<0.001$

$* * \operatorname{Sig} p<0.05$

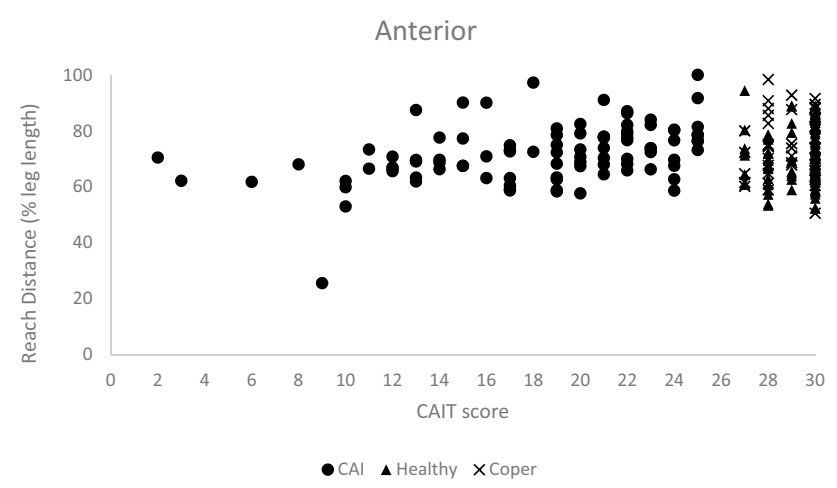

Fig. 1 CAIT score and anterior reach performance for participants

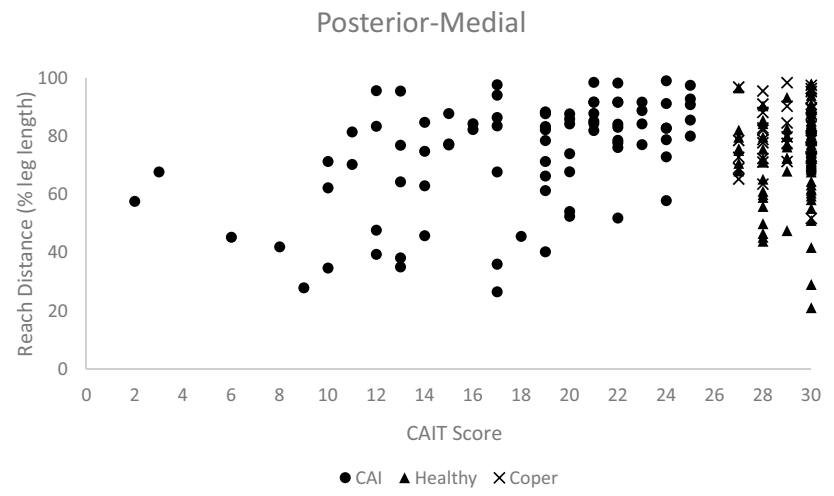

Fig. 2 CAIT score and posterior-medial reach performance for participants

clinician to understand a patient's feelings and perceptions, and determine the most appropriate rehabilitative approach.

Posterior reach directions showed slightly stronger correlations, highlighting increased perception of stability was recorded alongside increased reach distances posteriorly. This is despite the higher degree of reach difficulty in these directions from reduced visual feedback and increased reliance on somatosensory feedback [29]. This supports Sierra-Guzman and colleagues [10] results

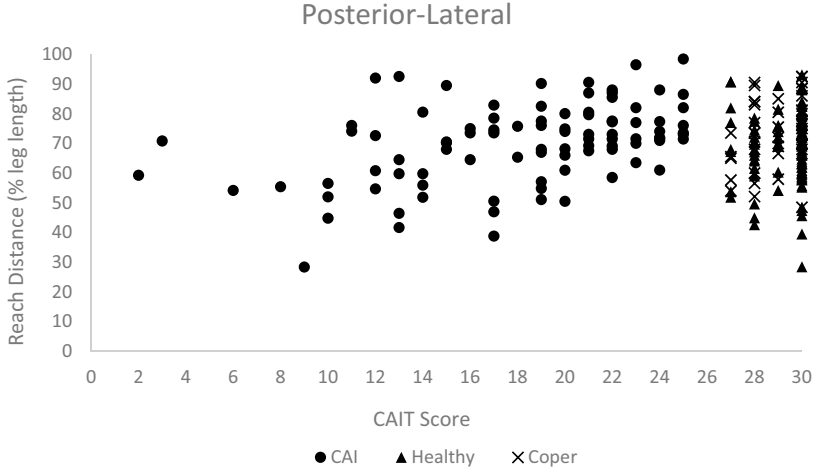

Fig. 3 CAIT score and posterior-lateral reach performance for participants

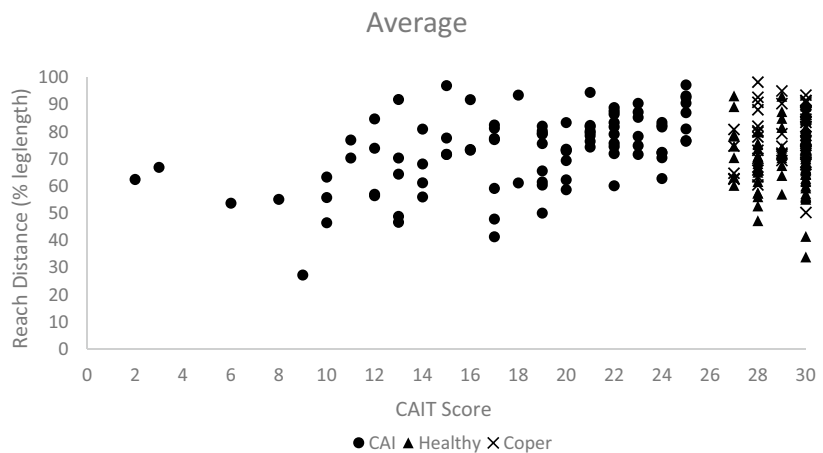

Fig. 4 CAIT score and average reach performance for participants

which found that the posteromedial reach direction was the variable with largest contribution to the CAIT ( $\beta=0.26$, $p=0.02$ ). Other factors may have a greater effect on the anterior reach direction which have not been controlled for in this study. Examples of which could be flexibility and strength, both of which have been shown to predict the variance and outcome [29-32]. Specifically, for the anterior reach direction, ankle dorsiflexion was significantly moderately correlated, but this was not apparent in the posterior reach directions [7]. 
The relationship between stability and the perception of stability becomes more prominent when preparing for return to play following an injury. Psychological readiness and physical performance have not been researched in people with CAI previously, however, it has been reported following ACL reconstruction (ACLR) surgery [33, 34]. Following ACLR, it has been reported that there were no functional differences for any of the tests conducted between the participants who did and did not return to sport. There was, however, a difference in the patient-reported outcome (International Knee Documentation Committee Subjective Knee Evaluation Form score: 95.52 vs 82.76, $p=0.03$ ) [34]. Fones et al. [33] also found that patient-reported outcomes were significantly lower in the people who did not return to sport in adolescents after 2 years post-surgery. The results suggest that PROs may be able to detect ongoing symptoms affecting patients' wellbeing that cannot be fully detected using traditional functional test batteries [34]. The work presented here supports previous literature that the psychological readiness had the strongest association with returning to sport participation, thus implying that the physical capacity to perform sport-related tasks is not as important [13]. This has not yet been researched in a CAI population. However, the current study provides evidence to warrant future research into the relationship between psychological readiness and physical performance for people with CAI.

For the copers and healthy groups, there was a small positive correlation between the CAIT and SEBT, however, this did not reach statistical significance. This is expected to be a result of the ceiling effect of the CAIT for these two groups, where a near-maximum score was required for study participation. This is important to consider when interpreting these results [35]. This is the first study to analyse copers. Interestingly, for healthy participants, a ceiling effect has not been acknowledged previously when analysing this relationship [10]. This may have influenced the results from the SierraGuzman [10] study. Future research may consider using more than one patient-reported outcome to assess perception of stability to reduce the potential impact of the ceiling effect for the coper group, and better understand this relationship, as well as for healthy participants if a comparison between groups is necessary.

\section{Strengths and limitations}

Due to the collaborative nature of the study, the sample size for the CAI and healthy groups was larger than that of previous research [5]. The coper group was a smaller size from one dataset.

This study is strengthened and limited by the diverse population from the four datasets used. The sample offered a diverse group from the general population from both the UK and Australia. This is in comparison to the majority of CAI studies have been in youth or college athletic populations.

Only one patient-reported outcome was used in this study - the CAIT. Therefore, it is unknown whether this result would be replicated using other patient-reported outcomes.

\section{Conclusion}

To summarise, there is a significant moderate correlation between SEBT performance and CAIT score in the CAI population. It highlights the discrepancies between objective and subjective stability (both the physiological and psychological performance variables), and reinforces the importance of using both types of measures for continual assessment in practice.

Author contributions Concept/idea/research design: LF, CRC, CEH, Writing: LF, FP, data collection: LF, FP, SAA, data analysis: LF, project management: LF, CRC, consultation (including review of manuscript before submitting): LF, CRC, FP, SAA, CEH.

Funding This research did not receive any specific grant from funding agencies in the public, commercial, or not-for-profit sectors. The data used in this project were collected from different projects supported by: The University of Strathclyde John Anderson Research Award, The University Sydney Post Graduate International Scholarship Award, and the Saudi Arabia PhD Scholarships.

Availability of data and materials https://doi.org/10.15129/90fa5891b5c2-4f6f-bf 15 -ab5594bbfa04

Code availability Not applicable.

\section{Declarations}

Conflict of interest No conflict of interest with any person, company, or institution.

Ethics approval All studies included in the analysis were approved by the respective University ethics committees (Department of Biomedical Engineering, University of Strathclyde and NHS R\&D (DEC 2018.243), The University of Sydney Human Research Ethics Committee (HREC) $(12808,15075,2015 / 84))$.

Informed consent All participants provided informed consent prior to participating in the study. No patient identity is revealed.

Consent for publication Not applicable.

Open Access This article is licensed under a Creative Commons Attribution 4.0 International License, which permits use, sharing, adaptation, distribution and reproduction in any medium or format, as long as you give appropriate credit to the original author(s) and the source, provide a link to the Creative Commons licence, and indicate if changes were made. The images or other third party material in this article are included in the article's Creative Commons licence, unless indicated 
otherwise in a credit line to the material. If material is not included in the article's Creative Commons licence and your intended use is not permitted by statutory regulation or exceeds the permitted use, you will need to obtain permission directly from the copyright holder. To view a copy of this licence, visit http://creativecommons.org/licenses/by/4.0/.

\section{References}

1. Gribble PA, Bleakley CM, Caulfield BM, Docherty CL, Fourchet F, Fong DTP, Hertel J, Hiller CE, Kaminski TW, McKeon PO, Refshauge KM, Verhagen EA, Vicenzino BT, Wikstrom EA, Delahunt E (2016) 2016 consensus statement of the international ankle consortium: prevalence, impact and long-term consequences of lateral ankle sprains. Br J Sports Med 50:1493-1495

2. Wikstrom EA, Mueller C, Cain MS (2020) Lack of consensus on return-to-sport criteria following lateral ankle sprain: a systematic review of expert opinions. J Sport Rehabil 29:231-237

3. Hubbard T, Wikstrom E (2010) Ankle sprain: pathophysiology, predisposing factors, and management strategies. Open Access J Sports Med 1:115-122

4. McKay GD, Goldie PA, Payne WR, Oakes BW (2001) Ankle injuries in basketball: injury rate and risk factors. Br J Sports Med 35:103-108

5. Doherty C, Delahunt E, Caulfield B, Hertel J, Ryan J, Bleakley C (2014) The incidence and prevalence of ankle sprain injury: a systematic review and meta-analysis of prospective epidemiological studies. Sports Med 44:123-140

6. Hiller CE, Nightingale EJ, Raymond J, Kilbreath SL, Burns J, Black DA, Refshauge KM (2012) Prevalence and impact of chronic musculoskeletal ankle disorders in the community. Arch Phys Med Rehabil 93:1801-1807

7. Terada M, Bowker S, Hiller CE, Thomas AC, Pietrosimone B, Gribble PA (2017) Quantifying levels of function between different subgroups of chronic ankle instability. Scand J Med Sci Sports 27:650-660

8. Hubbard TJ, Kramer LC, Denegar CR, Hertel J (2007) Correlations among multiple measures of functional and mechanical instability in subjects with chronic ankle instability. J Athl Train 42(3):361-366

9. Hertel J, Corbett RO (2019) An updated model of chronic ankle instability. J Athl Train 54:572-588

10. Sierra-Guzman R, Jiminez F, Abian-Vicen J (2018) Predictors of chronic ankle instability: analysis of peroneal reaction time, dynamic balance and isokinetic strength. Clin Biomech 54:28-33

11. Monahan A (2018) Psychological Readiness of athletes to return to play following injury. Master of Science, Georgia Southern University

12. Ivarsson A, Tranaeus U, Johnson U, Stenling A (2017) Negative psychological responses of injury and rehabilitation adherence effects on return to play in competitive athletes: a systematic review and meta-analysis. Open Access J Sports Med 8:27-32

13. Ardern CL, Osterberg A, Tagesson S, Gauffin H, Webster KE, Kvist J (2014) The impact of psychological readiness to return to sport and recreational activities after anterior cruciate ligament reconstruction. Br J Sports Med 48:1613-U50

14. Al Adal S (2020) Pain in people with chronic ankle instability, $\mathrm{PhD}$, The University of Sydney, https://ses.library.usyd.edu.au/ handle/2123/23244. Accessed 01 Apr 2021

15. Forsyth L (2021) Design, development and feasibility of a stability-based training package for people with chronic ankle instability. PhD, University of Strathclyde

16. Pourkazemi F, Hiller C, Raymond J, Black D, Nightingale J, Refshauge K (2016) Using balance tests to discriminate between participants with a recent index lateral ankle sprain and healthy control participants: a cross-sectional study. J Athl Train 51(3):213-222. https://doi.org/10.4085/1062-6050-51.4.11

17. Pourkazemi F (2014) Why do ankle sprains recur? PhD, The University of Sydney, https://ses.library.usyd.edu.au/handle/2123/ 11526. Accessed 01 Apr 2021

18. Gribble PA, Delahunt E, Bleakley CM, Caulfield B, Docherty CL, Fong DTP, Fouchet F, Hertel J, Hiller CE, Kaminski TW, McKeon PO, Refshauge KM, Van Der Wees P, Vicenzino W, Wikstrom EA (2014) Selection Criteria for Patients With Chronic Ankle Instability in Controlled Research: A Position Statement of the International Ankle Consortium. J Athl Train 49:121-127

19. Wright CJ, Arnold BL, Ross SE, Linens SW (2014) Recalibration and validation of the cumberland ankle instability tool cutoff score for individuals with chronic ankle instability. Arch Phys Med Rehabil 95:1853-1859

20. Hiller CE, Rershauge KM, Bundy AC, Herbert RD, Kilbreath SL (2006) The cumberland ankle instability tool: a report of validity and reliability testing. Arch Phys Med Rehabil 87:1235-1241

21. Delahunt E, Bleakley CM, Bossard DS, Caulfield BM, Docherty CL, Doherty C, Fourchet F, Fong DT, Hertel J, Hiller CE, Kaminski TW, McKeon PO, Refshauge KM, Remus A, Verhagen E, Vicenzino BT, Wikstrom EA, Gribble PA (2018) Clinical assessment of acute lateral ankle sprain injuries (ROAST): 2019 consensus statement and recommendations of the international ankle consortium. Br J Sports Med 52:1304-1310

22. Gribble PA, McLeod MM, Pietrosimone BG (2012) Influence of lower extremity kinematics on dynamic stability in patients with chronic ankle instability. Med Sci Sports Exerc 44:201-201

23. McKeon PO, Hertel J (2008) Systematic review of postural control and lateral ankle instability, part I: can deficits be detected with instrumented testing? J Athl Train 43:293-304

24. Olmsted LC, Carcia CR, Hertel J, Shultz SJ (2002) Efficacy of the star excursion balance tests in detecting reach deficits in subjects with chronic ankle instability. J Athl Train 37:501-506

25. Pozzi F, Moffat M, Gutierrez G (2015) Neuromuscular control during performance of a dynamic balance task in subjects with and without ankle instability. Int J Sports Phys Ther 10:520-529

26. Pionnier R, Decoufour N, Barbier F, Popineau C, SimioneauBuessinger E (2016) A new approach of the star excursion balance test to assess dynamic postural control in people complaining from chronic ankle instability. Gait Posture 45:97-102

27. Robinson R, Gribble P (2008) Support for a reduction in the number of trials needed for the star excursion balance test. Arch Phys Med Rehab 89:364-370

28. Cohen J (1988) Statistical power analysis for the behavioral sciences. Lawrence Erlbaum Associates, New York

29. Bulow A, Anderson JE, Leiter JR, MacDonald PB, Peeler J (2019) The modified star excursion balance and y-balance test results differ when assessing physically active healthy adolescent females. Int J Sports Phys Ther 14:192-203

30. Basnett CR, Hanish MJ, Wheeler TJ, Miriovsky DJ, Danielson EL, Barr JB, Grindstaff TL (2013) Ankle dorsiflexion range of motion influences dynamic balance in individuals with chronic ankle instability. Int J Sports Phys Ther 8:121-8

31. Gabriner ML, Houston MN, Kirby JL, Hoch MC (2015) Contributing factors to star excursion balance test performance in individuals with chronic ankle instability. Gait Posture 41:912-916

32. McCann RS, Crossett ID, Terada M, Kosik KB, Bolding BA, Gribble PA (2017) Hip strength and star excursion balance test deficits of patients with chronic ankle instability. J Sci Med Sport 20:992-996

33. Fones L, Kostyun RO, Cohen AD, Pace JL (2020) Patient-reported outcomes, return-to-sport status, and reinjury rates after anterior cruciate ligament reconstruction in adolescent athletes: minimum 
2-year follow-up. Orthopaed J Sports Med. https://doi.org/10. $1177 / 2325967120964471$

34. Werner JL, Berland JP, Mattcola CG, Toonstra J, English RA, Howard JS (2018) Decision to return to sport participation after anterior cruciate ligament reconstruction, part II: self-reported and functional performance outcomes. J Athl Train 53:464-474

35. Salkind NJ (2010) Encyclopedia of research design, vol 1. SAGE Publications, Thousand Oaks. https://doi.org/10.4135/97814 12961288
Publisher's Note Springer Nature remains neutral with regard to jurisdictional claims in published maps and institutional affiliations. 